\title{
Persuasión y tendencias de consumo
}

\author{
Fecha de recepción: 11 de octubre de 2011 - Aprobación: 11 de noviembre de 20111
}

\section{Hugo Mastrodoménico Brid}

\begin{abstract}
Resumen
En el presente artículo se revisan los conceptos fundamentales de la persuasión y las tendencias de consumo. Se consideran los aspectos que generan mayor polémica y se exponen los hallazgos más significativos en este campo. Igualmente se invita a la sociedad, especialmente a los estamentos académicos que tienen relación con este tema, a explorar las implicaciones de responsabilidad social y conveniencia del empleo de algunas técnicas persuasivas.
\end{abstract}

\section{Abstract}

This article reviews the fundamental concepts of persuasion and consumer tendencies. It also takes into account aspects that generate more controversy and presents the most significant findings in this field. Besides, the society, especially the academic institutions that deal with this topic, is invited to explore the implications of social responsibility and advisability of some persuasive techniques.

\section{Palabras clave}

Persuasión. Influencia. Tendencias, consumo, actitudes, publicidad

\section{Key words}

Persuasion. Influence. Tendencies. Consumption. Attitudes. Advertising

"El arte de la persuasión es el eje fundamental de las relaciones humanas propias de la convivencia civilizada, en contraposición a la intimidación y el uso de la fuerza, propias de la barbarie”.

\section{Introducción}

A la sociedad moderna parece sucederle algo similar a lo que ocurre con el universo, se expande en todas las direcciones. Tal cosa ocurre porque nuestro mundo resulta de una amalgama de toda clase de manifestaciones culturales que coexisten y compiten de una manera que podría resultarnos caó- tica. En el caso de la producción y consumo de bienes y servicios nos encontramos ante una verdadera barahúnda competitiva que nos abruma con miles de mensajes y ofertas para que compremos esto o aquello; semejante frenesí a veces nos lleva a pensar que la batalla por la prevalencia de los valores, unos que hablan del ser humano que 
vale por lo que es versus otros que hablan de valer por lo que se tiene, ya se decidió a favor de lo segundo. No obstante, en el seno mismo del mundo de la publicidad y el marketing también crece a pasos agigantados un movimiento de autocrítica que se pregunta si todo vale con tal de lograr una venta. Las empresas y las agencias se preguntan cada vez más si tiene sentido sacrificarlo todo en función del beneficio económico. Las dudas en este sentido van desde consideraciones ecológicas hasta interrogantes acerca de la salud mental de las personas y de la colectividad como es el caso de los desórdenes alimenticios, las depresiones por causa de no poder acceder a ciertos estilos de vida, etc. Puesto que estas consideraciones aún suelen ser secundarias para muchas empresas, el mundo académico es al que le corresponde proponer y desarrollar el debate sobre la función social de la publicidad y la sociedad de consumo. Desde la perspectiva de la psicología social uno de los temas que conviene observar con detenimiento es el de la persuasión y las tendencias de consumo. Si bien el intento de ejercer influencia sobre alguien más en el terreno de la persuasión es muchísimo más aceptable que casi todas las

\section{Reseña de autor \\ Hugo Mastrodoménico Brid \\ hugo.mastrodomenico@utadeo.edu.co \\ Universidad Jorge Tadeo Lozano}

Psicólogo de la Universidad Nacional de Colombia. Especialista en Comunicación/Educación de la Universidad Central. Magíster en Mercadeo Agroindustrial de la Universidad Jorge Tadeo Lozano. Ha sido profesor de las universidades Tadeo Lozano, Central, Sergio Arboleda, Politécnico Grancolombiano en las cátedras de Psicología de la Publicidad, General, Social, de la Comunicación, del consumidor, entre otras. Actualmente es Profesor Asociado I de la Facultad de Ciencias Humanas, Arte y Diseño de la Universidad Jorge Tadeo Lozano en el Programa de Publicidad. demás formas de influencia interpersonal, no todo lo que se hace en el campo de la persuasión es ético y defendible. En la búsqueda de aclarar y profundizar en los conceptos y prácticas que se ejercen cotidianamente en la persuasión con fines comerciales, el grupo de investigación Persuasión y tendencias de consumo, que hace parte de la línea de investigación Publicidad, sociedad, cultura y creatividad del Programa de Publicidad de la Universidad Jorge Tadeo Lozano, ha concluido dos proyectos de investigación y, actualmente, adelanta un tercero; todo ello con el fin de aportar al debate que se adelanta en el momento. EI presente artículo pretende ser una revisión del tema que da cuenta de los conceptos más importantes que se han decantado en este campo del conocimiento e igualmente hacer énfasis ante la academia y la sociedad sobre la importancia de esta temática como campo de investigación y debate ciudadano.

\section{Contenido}

La investigación sobre el tema "Persuasión y tendencias de consumo", desde un planteamiento fundado en la verificación científica en el campo de la psicología social, en diálogo interdisciplinario con otros abordajes, es un área del conocimiento que puede aportar evidencia empírica para comprender el comportamiento de la sociedad colombiana, especialmente cuando es impactado y condicionado por el éxito persuasivo de los mensajes y por las circunstancias situacionales y personales que lo presionan en un contexto de comercialización de bienes y servicios, al mismo tiempo esta investigación aporta elementos claves para la discusión sobre la dimensión ética de esta influencia interpersonal. 
Tanto en el contexto comercial como en el de bien público, la actividad publicitaria es por excelencia una labor persuasiva y el cumplimiento de sus metas radica fundamentalmente en lograr, en el primer caso, que se lleve a cabo la acción de compra de productos y servicios por parte de las personas que son el grupo objetivo de los mensajes; y en el segundo caso, en propiciar una toma de conciencia ciudadana que redunde en el mejoramiento de la interacción entre las personas y en la construcción de una sociedad más tolerante, incluyente y participativa.

Para lograr la eficacia, a la hora de persuadir, es necesario conocer a fondo a la persona persuadida con el fin de lograr su -ego implicación-, es decir, el involucramiento personal que ocurre cuando la persona no puede ser indiferente al estímulo recibido porque al prestarle atención, se emociona y reacciona en presencia de la propuesta, tal vez deseando y decidiendo hacer lo que le sugiere el persuasor; esto ocurre cuando el persuasor logra "tocar las fibras sensibles" del persuadido, hablarle de los asuntos que le conciernen, prometerle justamente lo que requiere o quisiera tener; y todo esto sólo es posible cuando se conoce la mentalidad y el entorno cultural de la persona, su manera de captar, sentir, pensar y comportarse.

Por todo lo anterior, el medio publicitario se beneficia con los estudios que buscan conocer más y mejor las tendencias que contribuyen a conformar los estilos de vida de las personas.

De otra parte, el mundo académico en su afán de contribuir en la producción de conocimiento está interesado en comprender profundamente el proceso de la persuasión, no sólo para brindarles a sus estudiantes, de publicidad y de otros programas, las mejores herramientas teóricas y prácticas que cualifiquen su futuro desempeño profesional, sino para contribuir al desarrollo de la sociedad, aportando conocimientos comprobados que resulten valiosos para el mejoramiento de la calidad de vida de los ciudadanos . La anterior afirmación resulta evidente cuando se tiene presente que el arte de la persuasión es el eje fundamental de las relaciones humanas propias de la convivencia civilizada, en contraposición, a la intimidación y el uso de la fuerza, propias de la barbarie.

Todos los esfuerzos que se hagan para comprender mejor el arte de la persuasión en las condiciones propias de la sociedad colombiana y latinoamericana contribuyen a fortalecer los intentos que se hacen en el país y en la región, con miras a construir una convivencia más tolerante y respetuosa de los derechos del otro.

\section{Persuasión}

La interacción humana inevitablemente implica el manejo de las influencias que se ejercen desde y hacia el individuo. Las personas no sólo llegan a los encuentros con el otro, sino que lo hacen con intenciones previamente establecidas o que surgen en el momento.

La comunicación es un proceso transaccional tanto en la transmisión de significados como en la posibilidad de influenciarse mutuamente. Al intentar ejercer influencia sobre otra persona, es muy difícil que no exista, al menos en teoría o en pequeña escala, la oportunidad de invertir la influencia. Al comunicarse, la personas tienen la esperanza de lograr que los demás ofrezcan la respuesta que se desea, aunque no
Todos los esfuerzos que se hagan para comprender mejor el arte de la persuasión en las condiciones propias de la sociedad colombianay latinoamericana contribuyen a fortalecer los intentos que se hacen en el país y en la región, con mirasa construir una convivencia más tolerante y respetuosa de los derechos del otro. 
se tenga conciencia de ello (Ross, 1978:75). El proceso transaccional es muy dinámico y bidireccional, y sólo concluye cuando no se está en presencia de otras personas. Este proceso representa mucho más que interacción con transmisión mutua de significados, pues se trata de la vida misma.

En el contexto ya descrito podemos definir la persuasión como una forma de influencia interpersonal en la que un individuo (persuasor o emisor) hace un intento deliberado tendiente a crear, cambiar o mantener las actitudes de otro (persuadido o receptor), quien tolera el intento que puede o no tener éxito (Mastrodoménico, 2003: 20).

Además de la persuasión hay otros tipos de influencia interpersonal que tienden a confundirse entre sí. Los otros tipos de influencia más relevantes son los siguientes: persuasión con el engaño, coerción, intimidación o uso de la fuerza, modelamiento e imitación, manipulación, adoctrinamiento, lavado de cerebro, identificación con el agresor y el síndrome de Estocolmo.

En la persuasión, un individuo intenta lograr que otro haga algo, pero el persuadido es libre de aceptar voluntariamente la propuesta o de no hacerlo. Existen dos tipos de persuasión: 1) por la ruta central, cuando se emplea la argumentación lógica y racional para convencer a las personas; y 2) por la ruta periférica cuando se hace apelación a los afectos, es decir, a las emociones, sentimientos y deseos para lograr el mismo propósito.

Este último caso, el de la persuasión por medio de los afectos, suele ser muy discutido y fácilmente designado erróneamente como 'manipulación', porque esta forma de influir sobre el otro, muchas veces, se encuentra en los límites de la ética. Ello es muy evidente en el caso de la persuasión por medio de la culpa dada en casos como 'si ya no me quieres, ya no tengo razones para seguir viviendo'. Debe tenerse en cuenta que, aunque la presión emocional en un caso así es muy fuerte, si la persona accede a continuar la relación por temor o por sentimientos de culpa, de todas maneras está accediendo voluntariamente.

Este tipo de estrategias emocionales incluyen el uso de la lástima, que les da el sustento a los mendigos. Otro recurso que suele funcionar es el humor-después de un buen chiste todos estamos más cerca del sí que antes-, también funciona muy bien el deseo -los estímulos eróticos, o los placeres de la comida. Incluso, las frases retadoras puede funcionar como recurso para la manipulación, por ejemplo: ¡usted qué va a ser capaz, esto es para gente valiente! No obstante, la publicidad hace un uso masivo de técnicas emocionales mucho menos molestas. Tal es el caso de, por ejemplo, emplear el halago y la exaltación de la vanidad del persuadido para lograr que haga lo que se desea de él. En este contexto se dicen cosas como "las personas inteligentes y de buen gusto, como tú...” curiosamente, hay técnicas de persuasión emocional que no despiertan críticas, como el caso del empleo de la ternura y el amor a los hijos para promocionar productos hacia las amas de casa.

Cuando en la persuasión interviene el engaño, también existe el libre albedrío pero es obvio que la persona persuadida está decidiendo sin conocer toda la información relevante o dando por ciertas premisas que el persuasor sabe muy bien que no lo son, por supuesto esta práctica es contraria a la 
ética y en algunos casos es abiertamente delictuosa.

En la coerción, intimidación o uso de la fuerza la persona se ve obligada a hacer algo en contra de su voluntad, de sus principios y de su propia conveniencia, pero tiene que hacerlo para evitar un evento o consecuencia más perjudicial todavía. La intimidación puede ser física ante una amenaza evidente de daño corporal, o psíquica ante una amenaza de hacer algo que no conviene, como revelar un secreto vergonzoso, o hacerle perder el empleo a un colega.

La manipulación, en el caso de ocurrir, consistiría en lograr que una persona hiciera algo que no quiere hacer, pero sin obligarla. Las circunstancias en las que podría pensarse que tal cosa ocurre, se limitan a los dudosos casos de la hipnosis, las drogas que pudiesen afectar la voluntad sin afectar la conciencia y, por último, al todavía más dudoso caso de la brujería.

El modelamiento e imitación es otro tipo de circunstancia humana en la que una persona termina ejerciendo influencia sobre otra, pero tiene la particularidad de ocurrir más por la mentalidad de la persona receptora de la influencia, que por las intenciones de quien la ejerce.

Cuando una persona se identifica con otra, esto es, cuando quiere parecerse a ella pues observa que posee justamente lo que el observador desea poseer, tal observación cuidadosa, muchas veces, termina en la —imitación-. Este mecanismo es muy frecuente en las relaciones humanas y es un método por el que asimilamos muchas de las características que conforman nuestra identidad. Los niños quieren ser como sus padres y los imitan, los adolescentes más jóvenes quieren ser como los mayores y, en ciertas circunstancias humanas, ocurre el mismo fenómeno. Por supuesto, los personajes y celebridades de los medios de comunicación, entre ellos los modelos de la publicidad, muchas veces se convierten en modelos a imitar.

Es importante resaltar que las personas no imitan a cualquier otra persona, sólo lo hacen con personas que tienen o parecen tener, aquello con lo que sueña el imitador; casi siempre se trata de cosas como belleza, riqueza, éxito, poder, afecto, felicidad, fama, placer, etc., es decir, cosas altamente valoradas socialmente y codiciadas en lo personal.

La publicidad es la única actividad en la que este proceso termina incluido en los intentos persuasivos, pues se utiliza ex profeso para aumentar la posibilidad de vender los productos. En la vida cotidiana, en términos generales, este proceso ocurre espontáneamente, pero en la publicidad es manejado con sumo cuidado cuando se eligen los modelos que tengan características envidiables, por las personas que componen el público objetivo al que se dirige el mensaje persuasivo.

El —adoctrinamiento- es el proceso de influencia que un grupo ejerce sobre un individuo que forma parte de él. Dado que la interacción humana exige la colaboración voluntaria de las personas involucradas, todos los grupos deben realizar algún tipo de adoctrinamiento para garantizar que los miembros se someten a las normas imperantes en el grupo.

Los grupos difieren en la magnitud del adoctrinamiento que realizan a sus miembros. Algunos grupos sólo adoctrinan una pequeña parte de la identidad de la persona y no intervienen en el resto de las facetas de
La publicidad es la única actividad en la que este proceso termina incluido en los intentos persuasivos, pues se utiliza exprofeso para aumentar la posibilidad de vender los productos. 
Una persona puedeser obligada, por la fuerza o la intimidación a hacer cosas, pero no puede ser obligada a creer, silo hace es porque decide hacerlo, yésa es una decisión que se toma ante sí mismo. la vida personal. Otros grupos intervienen en muchos más aspectos y algunos intervienen en todos los frentes de la vida del individuo, esto generalmente ocurre en el caso de algunas organizaciones militares y religiosas con ideologías extremas.

Pero es importante tener presente que el adoctrinamiento sólo puede tener lugar si la persona accede voluntariamente y permite ser adoctrinada, bien porque lo desea o bien porque lo busca, o porque está parcialmente interesada en él, o al menos porque no hace nada por evitarlo. Es imposible ser adoctrinado en contra de la voluntad, pues la persona cuando decide aceptar un cuerpo de ideas, lo hace ante sí misma. Una persona puede ser obligada, por la fuerza o la intimidación a hacer cosas, pero no puede ser obligada a creer, si lo hace es porque decide hacerlo, y ésa es una decisión que se toma ante sí mismo. La prueba de esta aseveración se encuentra en el caso del espionaje o en los intentos fallidos por hacer cambiar de religión a las personas en contra de su voluntad: en tales casos los individuos fingen creer, pero internamente se aferran a sus creencias anteriores para preservar su autoestima (Mann, 1973:68).

La expresión "lavado de cerebro" se escucha con mucha frecuencia y por su uso extendido parecería que el fenómeno es muy frecuente, pero si se observa con cuidado se encuentra que, como en el caso de la "manipulación", realmente es difícil que tal cosa ocurra. A veces se habla de lavado de cerebro para referirse al cambio de mentalidad de una persona como resultado de la influencia de un grupo, cosa que por supuesto ocurre frecuentemente; pero al analizar la situación se desconoce el adoctrinamiento y la aceptación voluntaria de la persona. De hecho, hablar de lavado de cerebro es una forma de victimizar a las personas y desconocerles su capacidad de discernir sobre lo que les conviene, especialmente cuando lo que eligen no les gusta.

Algunos autores usan el término "lavado de cerebro" para referirse a las torturas a las que son sometidos los prisioneros de guerra, quienes terminan declarando que están de acuerdo con las ideas de sus carceleros o ayudándoles en contra de su propio grupo (Garrison \& Loredo, 2002:353). Pero, nuevamente, el problema es si la persona sólo está evitando más torturas o maltratos, o si verdaderamente está convencida de la nueva ideología. La única forma de saberlo es observarla cuando es liberada y con el paso del tiempo, y sin presiones, puede declarar realmente lo que siente. Casi siempre las personas terminan pensando como lo hacían antes de las torturas y afirman que realmente nunca creyeron en lo que dijeron creer para evitar mayor daño.

Solamente se han observado unos pocos casos de personas que realmente sí terminaron convencidas de la ideología de sus torturadores. Tal fenómeno se llama identificación con el agresor y es fruto de graves perturbaciones psíquicas, pues normalmente las personas que sufren maltratos terminan odiando a sus perpetradores, no justificándolos ni asumiendo como válidas las ideas que sustentan la agresión y por las que fueron objeto de vejación.

Por último, el síndrome de Estocolmo que es un fenómeno asociado a los secuestros, consiste en que, por la convivencia propia de los secuestros, secuestradores y secuestrados terminan estableciendo vínculos personales que muchas veces involucran sentimientos favorables, sin incluir la 
aceptación de la ideología del agresor ni la justificación de la agresión; simplemente se trata de comprender a la persona y reconocerle algunas cualidades o buenas acciones.

Volviendo a la persuasión, y teniendo en cuenta que su fin es el de crear, cambiar o mantener las actitudes del receptor, es necesario definir correctamente el concepto de actitud, pues se trata de otra palabra que tiene muchas acepciones en el lenguaje cotidiano.

Actitud es una predisposición valorativa, favorable o desfavorable, que dirige nuestra conducta con respecto a los elementos de la realidad. Esta definición deja en claro la diferencia entre actitud y conducta. Conducta es lo que hacemos, actitud es lo que estamos dispuestos a hacer. Los términos cotidianos que se pueden considerar sinónimos de actitud son: preferencias, gustos, opiniones, disposiciones, intenciones, decisiones, valores, etc.

Toda actitud tiene tres componentes: 1 ) el afectivo, lo que sentimos por algo o alguien; 2) el cognitivo, lo que pensamos de ese mismo algo o alguien; y 3) el decisivo o preconductual, lo que estamos dispuestos a hacer con respecto a ese mismo algo o alguien, es decir, la tendencia de comportamiento hacia dicho elemento de la realidad.

La persuasión busca en últimas que la persona haga algo, es decir, busca una conducta, pero es obvio que para lograr esa conducta se necesita primero que la persona esté dispuesta a llevarla a cabo; es lo que en el campo de la propaganda (persuasión con fines ideológicos) suele llamarse "crear conciencia". Se trata de cambiar la mentalidad de la persona para que ahora sí esté lista a comportarse como se espera de ella. En el campo comercial, obviamente, la conducta esperada es la compra del producto o servicio, pero para llegar a ello es indispensable cambiar las actitudes de la persona para que esté dispuesta (actitud favorable) a efectuar la adquisición del producto o servicio.

Son muchas las variables y condiciones que inciden en el éxito de la persuasión, entendida como una respuesta libre del persuadido que es justamente la esperada por el persuasor. Pero si se tratara de escoger cuál es el aspecto más importante en este punto, sin duda alguna habría que decidirse por la actitud inicial, esto es, el punto de vista que la persona ya posee acerca del asunto que se le plantea antes de producirse la propuesta.

Existen muchas ocasiones en las cuales persuadir a una persona acerca de algo específico es absolutamente imposible, y, en otros casos, la imposibilidad no es total pero sí sumamente marcada; existen otras donde la posibilidad de lograr el tan anhelado sí, no es tan difícil y finalmente existen otros casos donde lograr la aceptación es relativamente más fácil. Esto se debe a que lo propuesto coincide con el sistema general de valores de la persona.

Pero cuando no existe tal coincidencia, los persuasores se enfrentan a una labor muy difícil y, como ya se dijo, algunas veces imposible. La verdad es que las personas tienden a aferrarse tendenciosamente a las creencias que ya poseen.

Desde los primeros estudios de la psicología social fue evidente que la información inicial que poseen las personas, tiende a sesgar los juicios que realizan a posteriori (Kelley, 1950 citado por Mann, 1973:124). Pero en algunos casos no se trata de poseer cierta información y aferrarse a ella, sino que las personas tienen "opiniones fuer- 
tes" sobre un tema específico y se niegan a exponerse o escuchar argumentos contrarios o diferentes, y en el caso de verse obligados a oírlos; no los entienden, y en el caso de entenderlos, se las arreglan para minimizar el monto de verdad que puedan contener y, tergiversándolos, terminan por reafirmar su prejuicio original. Es evidente que la memoria es selectiva y las personas emplean el mecanismo de acordarse sólo de los aspectos de las vivencias que les confieren la razón, al tiempo que olvidan las negativas. Por extraño que pueda parecer, este fenómeno se ha observado incluso en los debates científicos (Morin, 1994:16).

Estos fenómenos llevan a los expertos a concluir que las campañas que buscan producir efectos en el campo de los temas álgidos, es decir, los que casi siempre están en el terreno de la propaganda política, religiosa o cívica, más que cambiar las actitudes tienden a reforzar las convicciones preexistentes (Balle, 1991:429).

La conclusión es que persuadir a las personas no es una tarea fácil y, por ello, muchas personas prefieren recurrir directamente al uso de la fuerza, tal como se hizo a lo largo de gran parte de la historia y la prehistoria humanas.

\section{Tendencias de comportamiento}

En el mundo del marketing y la publicidad, conocer al consumidor se ha convertido en un imperativo ineludible, la razón es que el alto nivel de competencia obliga a las empresas a intentar "posicionarse" en la mente y en el corazón de las personas, con el fin de asegurar las ventas y con ella su supervivencia en los mercados.

De las famosas “investigaciones motivacionales" con las que se inauguró la parti- cipación de los psicólogos, y otros profesionales de las ciencias humanas en el mundo de la comercialización de productos y servicios, se pasó a los estudios de personalidad del consumidor, de allí a los estudios de los estilos de vida que permitieron combinar la información demográfica, tradicionalmente utilizada por los profesionales del marketing y la publicidad, con la información psicográfica que incluía aspectos cualitativos como deseos, temores, opiniones y demás variables psicológicas internas (Mastrodoménico \& Gómez, 2007: 7).

Actualmente se comienza a imponer una nueva metodología conocida como "neuromarketing" en la cual mediante una tomografía axial computarizada, se hacen escaneos del cerebro en presencia de estímulos comerciales como logo símbolos y logotipos o ante situaciones claramente asociadas a las marcas o a las situaciones de consumo (Braidot, 2007:27). El neuromarketing está aún muy lejos de ser una herramienta precisa dado que los conocimientos actuales sobre los procesos cerebrales son insuficientes, pero aun así, la herramienta está siendo utilizada, incluso en Colombia ya hay campañas publicitarias cuyos componentes fueron escogidos por este procedimiento.

El neuromarketing amenaza con convertirse en un verdadero limitante de los derechos humanos debido a que representa una intromisión en la intimidad de los pensamientos y sentimientos de las personas; $y$ con el desarrollo tecnológico en este campo, se podría llegar no sólo a establecer qué pasa en el cerebro de una persona, sino a encontrar formas de influir directamente en él.

Cuando se estudian las tendencias de comportamiento de los consumidores no se observa tanto cómo se conducen las per- 
sonas, sino más bien cómo lo harán en un futuro, o cuáles comportamientos actuales se fortalecerán con el paso del tiempo y cuáles perderán vigencia.

En general, en nuestro país las tendencias son producto de la imitación de los comportamientos que se imponen en los países desarrollados, especialmente, en Estados Unidos como una expresión del llamado "malinchismo", que es la tendencia a adoptar el estilo de vida de los grupos de anticipación, esto es, de los grupos a los que "no pertenecemos pero quisiéramos hacerlo".

Desde la perspectiva intra psíquica, las tendencias corresponden al componente decisivo o pre conductual de las actitudes, es decir, a la disposición mental a comportarse de una u otra manera ante ciertas circunstancias, llegado el momento. Pero el componente decisivo, también llamado por algunos autores componente volitivo, porque representa la voluntad de hacer o no hacer algo, no es una entidad autónoma, sino que es el resultado de la correlación de fuerzas de los otros dos componentes: el afectivo y el cognitivo; en otras palabras: "lo que estamos dispuestos a hacer depende de lo que sentimos y de lo que pensamos con respecto a cualquier elemento de la realidad".

Desde la perspectiva del marketing y la publicidad, la importancia de las tendencias radica en la siguiente premisa: aunque una persona no sea consumidora actual de un producto, porque tal vez sea muy joven y no tiene el dinero para comprarlo o por cualquier otra razón, su voluntad y decisión de hacerlo incidiría en que, con el pasar del tiempo y al comenzar a ganar su propio dinero, muy seguramente esa persona se apresurará a realizar su fantasía. En el campo comercial es una verdad reco- nocida que comprender las tendencias de comportamiento es un factor clave de éxito en la dirección estratégica de marketing.

Comercialmente, una tendencia es una propensión o inclinación hacia cualquier producto o servicio. El concepto de tendencia es diferente al concepto de 'moda'. La moda también conlleva una predisposición hacia la acción de compra, pero en este último caso se trata de algo de carácter momentáneo, las modas son efímeras, llegando algunas a permanecer un poco más que otras.

Una tendencia implica cierta estabilidad en el mundo intra psíquico de la persona, se trata de una predisposición perdurable que incidirá en las decisiones de la persona por largo tiempo o, incluso, por toda la vida. Las tendencias se consolidan más lentamente y, por ello, también son más profundas. Un ejemplo claro de tendencia es la preferencia por los alimentos saludables. Una tendencia puede contener muchas modas que se insertan en ella. Por ejemplo, en un momento dado puede estar de moda consumir verduras orgánicas y seis meses después estar de moda consumir jugos orgánicos, en este caso, la tendencia consiste en consumir alimentos orgánicos.

Toda tendencia involucra una intención y una inclinación. La inclinación consiste en sentir atracción por algo o alguien, pero dicha inclinación puede ser consciente o inconsciente y voluntaria o involuntaria, dependiendo de si la persona sabe que está siendo atraída hacia un comportamiento y si lo hace a propósito.

La intención necesariamente es consciente y voluntaria, y de esta manera implica un propósito claro de acercarse al objeto de la atracción. En términos comer-
Desde la perspectiva intra psíquica, las tendencias corresponden al componente decisivo o pre conductual de las actitudes, es decir, a la disposición mental a comportarse de una u otra manera ante ciertas circunstancias, llegado el momento. 
ciales, la intención es la decisión ya tomada, y, ojalá comunicada, de comprar algo en cuanto sea posible.

Cuando una intención es aceptada ante el propio yo, la persona tiene que racionalizarla, es decir, justificarla lógicamente ante sí mismo y ante los demás. Independientemente de si el origen de una decisión es puramente emocional, toda persona requiere al menos un poco de racionalidad para decidirse a incluir algo en su espacio vital, en este caso, a gastar el dinero necesario y efectuar la compra. Después de cumplir las etapas intra psíquicas, lo único que hace falta es llevar a cabo las externas: disponer del dinero, y ubicar el lugar y el momento propicio.

En el ámbito de la administración de empresas y del marketing estratégico, se habla con insistencia de 'mega tendencias' que son propensiones relacionadas con el consumo que han adquirido un carácter global; existen varias listas de mega tendencias, pero casi todas incluyen la importancia creciente de la Internet en muchas actividades humanas, igualmente la preferencia por las nuevas tecnologías, especialmente, en el campo del entretenimiento, el desarrollo de la nanotecnología y la biotecnología, la preocupación por el cuidado del planeta, el acercamiento hacia la perspectiva oriental específicamente la asiática, la preponderancia del idioma inglés, el aumento de las migraciones y del intercambio cultural, la mayoría de edad de una buena parte de la población mundial, especialmente en los países desarrollados, la creciente participación de la mujer en los asuntos públicos, el aplanamiento de las estructuras organizacionales laborales, la soledad personal de una inmensa cantidad de personas, el aumento de las inquietudes espirituales y el culto a la belleza y a la juventud. (Naisbitt \& Aburdene, 1990)

En el año 2008, la empresa DDB Worldwide Communications Inc. efectuó un estudio que le permitió encontrar cinco tendencias que caracterizan al consumidor del futuro en el mundo. Según esta investigación, las personas exigirán que las promociones se apeguen a la verdad, esta tendencia es aplicable tanto al marketing comercial como al marketing político.

El mismo estudio encontró que la segunda tendencia tiene que ver con la búsqueda de diferenciarse. Las personas esperan encontrar la manera de expresarse ante los demás con una versión propia de las cosas. Las empresas tienen que encontrar alguna manera de evitar la uniformidad y permitir a las personas refirmar su identidad de manera independiente. La tercera tendencia tiene que ver con la exigencia del consumidor en cuanto a poder encontrar toda la información y la guía requeridas de manera fácil y económica. $\mathrm{La}$ cuarta tendencia se relaciona con el afecto. El consumidor del futuro le dará mucha importancia a asegurarse de dar y recibir una buena cantidad de manifestaciones de amor por parte de la pareja, la familia, los semejantes, etc.

Finalmente, el mencionado estudio encontró que el consumidor del futuro estará busca símbolos externos de pertenencia, es decir, productos y servicios que le garanticen hacer parte de alguna organización humana con la que pueda tener alguna afinidad (Munévar, 2008).

JWT, una agencia de publicidad que monitorea cada año los hábitos y tendencias de los consumidores en todo el mundo, ha 
elaborado otra lista de las tendencias más importantes que rigen el comportamiento del consumidor. Entre los hallazgos más importantes, se menciona que los consumidores europeos parecen estar cambiando su tradicional costumbre de mostrarse reacios a la influencia norteamericana; como prueba de ello actualmente Europa consume más alimentos ricos en calorías que en décadas anteriores, lo que implica un aumento en el peso de los individuos. Algo similar ocurre con el consumo de tabaco (¿Para dónde va la gente?, 2007).

La misma agencia encontró también que el ciudadano actual está dedicando menos tiempo a dormir. El promedio de horas de sueño en Estados Unidos es de 6,9. Parece lícito deducir de estos datos, que el tiempo extra que se ha otorgado al entretenimiento está haciendo que el sueño disminuya. El entretenimiento que antes era suministrado por grandes empresas dedicadas a tal fin, hoy en día la misma persona se lo procura mediante las nuevas tecnologías, especialmente las asociadas a Internet.

Las nuevas tecnologías están incidiendo en la desaparición de las barreras entre los diferentes grupos de edades en muchos aspectos de la vida. Debido al fácil acceso a las fuentes de información, los niños de hoy hacen cosas de adultos y viceversa. Un hecho que parece estar relacionado con esto es el incremento en el tiempo que los hijos viven en casa de sus padres. En este mismo orden de ideas, se encuentra que últimamente ha sido identificado un nuevo segmento de mercado al que se ha dado en llamar 'adultescentes', es decir, personas adultas que deciden comportarse como adolescentes negándose a madurar. Se visten como lo hacen los muchachos que tienen 15 o 20 años menos que ellos, escuchan su música, se divierten en los mismos lugares, compran las mismas marcas sin que importe el precio, pues son personas que ya están en la etapa productiva de su vida en el medio laboral, y tienen dinero. Por su puesto el comercio ha reaccionado ofreciendo productos y servicios enfocándose en ellos (Los adultescentes, 2006).

La quinta tendencia identificada por el estudio de JWT es incremento de negocios propios por parte de mujeres que quieren pasar más tiempo en el hogar con sus hijos. La sexta es la búsqueda de experiencias placenteras inmediatas. Al contrario de las generaciones pasadas que perseguían acumular para el futuro, los consumidores actuales están llevando a cabo actividades como viajar a edades mucho más tempranas. La séptima tendencia es la de buscar la verdad en lo que se mencionada acerca de los productos y las personas. La última tendencia identificada por este estudio es nuevamente la de alimentarse de manera saludable (¿Para dónde va la gente?, 2007).

Para el marketing y la publicidad, la importancia de las tendencias no sólo radica en que las personas compran o dejan de comprar cierto producto por coincidir o no con su tendencia. Es importante también el hecho de que la persona que posee la tendencia pero no es consumidora actual del producto (por ser quizás muy joven y no tener el dinero para comprarlo), al tener la voluntad y decisión de hacerlo incidiría en que, al pasar del tiempo y comenzar a obtener sus propios ingresos, muy probablemente adquiera el producto. En el campo comercial, comprender las tendencias de comportamiento es un factor clave de éxito en la dirección estratégica de marketing. 
En Colombia, al igual que muchos países del tercer mundo, muchas de las tendencias que terminan imponiéndose son producto de la imitación de los comportamientos que se observan en las personas de los países desarrollados, especialmente en Estados Unidos, como una expresión del llamado "malinchismo", que es la tendencia a adoptar el estilo de vida de los grupos de anticipación, es decir, de los grupos a los que no pertenecemos pero deseamos hacerlo. Como el caso del joven que sueña con pertenecer al mundo de la farándula pero su vida no tiene nada que ver con tal mundo. Probablemente muchas de sus escogencias tendrán que ver con los símbolos externos propios de dicho mundo. No obstante, el actual ascenso de la postmodernidad que implica un ascenso del sujeto, lleva a que muchas personas, especialmente los jóvenes, tomen como modelos de imitación a diferentes personas de diferentes grupos, culturas y subculturas, formando su propia identidad como un agregado de influencias diversas.

En Colombia también se han realizado algunos estudios sobre las tendencias. Uno de ellos, publicado por la revista Dinero (2002) encontró que las tendencias más significativas del consumidor colombiano eran las siguientes: 1) Tener menos dinero, pero usarlo mejor. 2) Exigir que las cosas puedan realizarse fácilmente. 3) Preocuparse mucho por la seguridad. 4) Gastar en productos altamente gratificantes pese a ser un gasto racional. 5) Llevar una vida saludable. 6) Acceder a información que le permita conocer las tendencias del exterior para guiar sus elecciones. 7) Poner la autoestima personal como prioridad (El nuevo consumidor colombiano, 2002).

En el año 2006, la firma YanHaas realizó 1300 encuestas en 6 regiones del país y encontró que, en términos individuales, el colombiano se considera una persona sociable, autosuficiente y moderada frente al cambio. También se encontró que, en comparación con estudios anteriores, el colombiano era menos hedonista, más planificador, más satisfecho con su esquema corporal y considera al dinero como un medio más que un fin. En lo social, le da un alto valor a la familia y se observó que la mujer ha adquirido un protagonismo aún mayor en los roles relacionados con el consumo ( $\mathrm{La}$ transformación del consumidor, 2006).

En Colombia también se detecta la tendencia mundial de disponer de menos tiempo, un ejemplo de esto consiste en el concepto del día domingo, el cual se empleaba como un día de descanso, actualmente es dedicado a actividades como hacer compras e incluso diligencias. Los domingos son hoy en Colombia el segundo día de la semana con más altas ventas después del sábado. Los supermercados y hasta las notarías y bancos están modificando sus horarios para adaptarse a estas nuevas tendencias que, por supuesto, incluyen cambios en los horarios nocturnos (Espejo, 2006).

La empresa Raddar S.A. llevó a cabo un estudio que duró cuatro años y efectuó más de 30.000 encuestas en 13 ciudades del país para estudiar el comportamiento del consumidor colombiano en lo referente al modo de gastar el dinero, y encontró, para el año 2007, que el gasto del colombiano promedio era $\$ 349.682$ mensuales, $32 \%$ de los cuales se gastaban en comida mientras que a la vivienda se le dedicaba el $24 \%$. Los gastos en transporte y comunicaciones sumaron 18,4\%. El 4,6\% se empleaba en vestuario y calzado. En cultura y diversión el monto fue de 3,1\%; 
en salud $4,6 \%$; en educación $4,7 \%$ y en otros gastos $8,4 \%$.

A manera de conclusión, cabe anotar que la sociedad, en especial sus estamentos académicos, está en mora de investigar a fondo y propiciar un debate acerca de una multitud de prácticas persuasivas que hacen parte de la vida cotidiana de las personas, sin que antes se haya llevado a cabo un análisis crítico de los peligros que involucra la persuasión. La sola rentabilidad económica de tales prácticas, que puede indicarnos un cierto nivel de aceptación por parte de un número suficiente de personas, no puede ser el único criterio para permitir que sean de libre utilización en nuestra cultura. Puesto que siempre habrá diversidad de puntos de vista éticos acerca de cualquier conducta considerada dudosa, pues la postura correcta no puede ser la prohibición ni la permisividad total solo por complacer a los partidarios de alguna de las posturas más extremas. La solución del dilema, tal vez, deba quedar en manos de los individuos a los que van dirigidos los mensajes y las estrategias persuasivas: los consumidores, pero consumidores informados, conocedores de los alcances, limitaciones y peligros de las diferentes técnicas para influir sobre su conducta. Si tales conocimientos hacen parte del acervo con el que un consumidor se expone ante un intento persuasivo $y$, con todo, decide aceptar la propuesta, nadie puede desconocer que estamos ante un ejercicio de la voluntad soberana de una persona que elige libremente su camino hacia lo que considera su felicidad.

\section{Bibliografía}

1. ¿Para dónde va la gente? (22 de Enero de 2007). Semana .

2. Aburdene, P. (2005). Megatendencias 2010: El surgimiento del capitalismo consciente. Bogotá: Norma.

3. Arellano, R. (2002). Comportamiento del consumidor. Enfoque América Latina. México: McGraw-Hill.

4. Assael, H. (1999). Comportamiento del consumidor. México: Thomson.

5. Balle, F. (1991). Comunicación y sociedad. Bogotá: Tercer Mundo.

6. Baran, S. (1998). Comunicaión masiva en hispanoamérica. México: McGraw-Hill.

7. Bárcena, F. (1997). El oficio de la ciudadanía. Introducción a la educación política. Barcelona: Paidos.

8. Baron, R., \& Byrne, D. (1998). Psicología social. Madrid: Prentice Hall Iberia.

9. Blackwell, R., Miniard, P., \& Engel, J. (2002). Comportamiento del consumidor. México: Thomson.

10. Braidot, N. (2007). El neuromarketing le apunta a la cabeza. Tiempo de mercadeo, 3 (12), 27-32.

11. Brown, J. (1978). Técnicas de persuasión. Madrid: Alianza.

12. El nuevo consumidor colombiano. (2002). Dinero, 30-32.

13. Espejo, A. (28 de Mayo de 2006). Y los domingos se convirtieron en sábados. El Tiempo . 
14. Feldman, R. (1998). Psicología. México: McGraw-Hill.

15. Garrison, M., \& Loredo, O. (2002). Psicología. México: McGraw-Hill.

16. Gill, L. (1972). Publicidad y psicología. Buenos Aires: Psique.

17. Hawkins, D., Best, R., \& Coney, K. (2004). Comportamiento del consumidor. México: McGraw-Hill.

18. Key, W. (1987). Seducción subliminal. México: Diana.

19. Kymlicka, W., \& Norman, W. (1997). El retorno del ciudadano. Una revisión reciente en teoría de ciudadanía. La Política. Ciudadanía, el debate contemporáneo, 3.

20. La transformación del consumidor. (2006). Dinero, 100-101.

21. Lindstrom, M. (2009). Compradicción. Bogotá: Norma.

22. Los adultescentes. (1 de Marzo de 2006). Semana .

23. Mann, L. (1973). Elementos de psicología social. México: Limusa.

24. Mastrodoménico Brid, H. (2011). ¿El erotismo oculto vende? PひM, 364, 8-11.

25. Mastrodoménico, H. (2003). La influencia de la información inicial suministrada por el proponente, sobre las conclusiones a las que llegan los grupos de discusión en el aula. Tesis de Grado. Bogotá: Universidad Central.

26. Mastrodoménico, H. (2008). La influencia persuasiva de los grupos de referencia sobre las tendencias y hábitos de consumo de tecnología (Vol. 3). Bogotá: Universidad Jorge Tadeo Lozano.

27. Mastrodoménico, H. (1996). Psicología de la comunicación. Bogotá: Universidad Jorge Tadeo Lozano.

28. Mastrodoménico, H., \& Gómez, J. (2007). Perfil del consumidor joven colombiano para empresas. Notas de Marketing, 0 .

29. McGuigan, F. (1984). Psicología experimental. Enfoque metodológico. México: Trillas.

30. Morin, E. (1994). Introducción al pensamiento complejo. Barcelona: Gedisa.

31. Mucchielli, A. (1998). Psicología de la comunicación. Barcelona: Paidós.

32. Mucchielli, R. (1977). Psicología de la publicidad y de la propaganda. Bilbao: Mensajero.

33. Munévar, T. (20 de Febrero de 2008). Los consumidores del futuro en busca de orientación y guía. Portafolio .

34. Naisbitt, J., \& Aburdene, P. (1990). Megatendencias 2000. Madrid: Norma.

35. Ross, R. (1978). Persuasión. México: Trillas. 